\title{
Influência do regime de cortes sobre a produção e valor nutricional de trigo cv. BRS Umbu para forragem
}

\author{
Cutting system influence on production and nutritional value of wheat cv. BRS Umbu for \\ forage
}

\author{
Rodolfo Carletto ${ }^{1}$, Guilherme Fernando Mattos Leão ${ }^{2 \star}$, Mikael Neumann ${ }^{1}$, Egon Henrique Horst ${ }^{3}$ \\ ${ }^{1}$ Universidade Estadual do Centro Oeste, Guarapuava, PR, Brasil. \\ ${ }^{2}$ Universidade Federal do Paraná, Curitiba, PR, Brasil. *Autor para correspondência: gfleao@hotmail.com \\ ${ }^{3}$ Universidade Estadual de Londrina, Londrina, PR, Brasil.
}

Submissão: 06/04/2019 / Aceite: 22/06/2020

\begin{abstract}
RESUMO
A otimização do manejo de pastagens é essencial para que se obtenha níveis produtivos superiores, e os cereais de duplo propósito têm se destacado, podendo ser utilizado visando diferentes objetivos dentro da propriedade através de diversas estratégias de manejo. Objetivou-se avaliar a produção de biomassa e o valor nutricional da forragem do trigo (Triticum aestivum L. cv. BRS Umbu) sob influência de regime de cortes sucessivos simulando situações de pastejo. O delineamento experimental utilizado foi em blocos ao acaso, composto por três tratamentos (sem corte - controle; um corte realizado; e dois cortes realizados) com cinco repetições. Para produção de biomassa seca acumulada foram observados valores médios de $10.926 \mathrm{~kg} \mathrm{ha}^{-1}$ para o tratamento sem corte, $7.989 \mathrm{~kg} \mathrm{ha}^{-1}$ para o tratamento com um corte e $3.514 \mathrm{~kg} \mathrm{ha}^{-1}$ para o tratamento com dois cortes. Houve diferença entre a relação folha:colmo, sendo este fator reduzido de acordo com o aumento no número de cortes $(4,14 ; 2,36$ e 2,24 para os sistemas sem corte, com um e com dois cortes, respectivamente). Na composição bromatológica não foram encontradas diferenças significativas para os teores de proteína bruta, fibra em detergente ácido e fibra em detergente neutro. $\mathrm{O}$ aumento no número de cortes não reduz o rendimento de biomassa verde acumulado, mas, uma diminuição expressiva no percentual de folhas pode levar a menores produções de biomassa seca. Como a bromatologia não foi alterada pelo regime de cortes, percebe-se melhores resultados produtivos em sistema de um corte e/ou pastejo.
\end{abstract}

PALAVRAS-CHAVE: duplo propósito, produção de biomassa seca, proteína, Triticum aestivum L.

\begin{abstract}
The optimization of pasture management is essential for obtaining higher productive levels, and dualpurpose cereals have stood out and can be used for different purposes within the property through different management strategies. The objective was to evaluate the biomass production and the nutritional value of wheat forage (Triticum aestivum L. cv. BRS Umbu) under the influence of successive cutting regimes simulating grazing situations. The experimental design used was in randomized blocks, composed of three treatments (without cut - control; one cut; and two cuts performed) with five replications. For accumulated dry biomass production, average values of $10,926 \mathrm{~kg} \mathrm{ha}^{-1}$ were observed for the treatment without cutting, $7,989 \mathrm{~kg} \mathrm{ha}^{-1}$ for the treatment with one cut and $3,514 \mathrm{~kg} \mathrm{ha}^{-1}$ for the treatment with two cuts. There was a difference between the leaf: stem ratio, this factor being reduced according to the increase in the number of cuts $(4.14 ; 2.36$ and 2.24 for without cut, with one and two cuts, respectively). In the bromatological composition, no significant differences were found for the crude protein, acid detergent fiber and neutral detergent fiber contents. The increase in the number of cuts does not reduce the accumulated green biomass yield, but a significant decrease in the percentage of leaves can lead to lower dry biomass production. As bromatology was not altered by the cutting regime, better productive results can be seen with one cut and/or grazing system.
\end{abstract}

KEYWORDS: dual purpose, dry biomass production, protein, Triticum aestivum $\mathrm{L}$.

\section{INTRODUÇÃO}

Os sistemas baseados na utilização de pastagens são a forma mais comum de exploração animal, 
mesmo havendo diversas limitações de uso, sobretudo na época mais fria, onde observa-se déficit de crescimento e senescência das pastagens de ciclo perene (NEUMANN et al. 2014). Condições como estas promovem baixos índices de desempenho animal, e o principal desencadeador é a diminuição tanto da quantidade como da qualidade da forragem disponível nesses determinados períodos (CARLETTO et al. 2015). Desta forma, a otimização do manejo de pastagens é essencial para que se obtenha níveis produtivos superiores. HOLLAND et al. (2019) afirmam que o cultivo com duplo propósito, além de fornecer forragem em épocas normalmente deficitárias, possibilitam repouso da pastagem, aumento da capacidade de carga animal, aumento das taxas de crescimento animal e auxiliam no manejo de ervas daninhas e resíduos de culturas.

Em muitas regiões, onde no período de inverno existe a ocorrência de geadas severas, a cultura do trigo recebe destaque como forragem, uma vez que possui uma maior resistência ao congelamento quando comparado aos demais cereais de inverno (SILVA et al. 2008).

A cultivar de trigo BRS Umbu tem se destacado como um cereal de duplo propósito (QUATRIN et al. 2017), podendo ser utilizado visando diferentes objetivos dentro da propriedade através de diversas estratégias de manejo, até mesmo melhorando o desempenho da cultura subsequente pelo acumulado de matéria orgânica deixado no solo (DEEN et al. 2019). Sendo assim, o trigo de duplo propósito deve apresentar um rápido estabelecimento e alta capacidade de perfilhamento, disponibilizando massa de forragem de forma precoce, além de sequencialmente, ofertar boa produtividade de grãos (BARTMEYER et al. 2011, SANTOS et al. 2015). Todavia, mais especificações sobre as características do uso desse trigo como forragem são necessárias, especialmente no que diz respeito a sua resistência a pastejo sucessivos e produção de biomassa sem prejudicar à região meristemática da planta, possibilitando a elongação dos entrenós e viabilizando a produção de grãos futura (FONTANELI et al. 2009).

Dessa forma, objetivou-se neste trabalho avaliar a influência do regime de cortes sucessivos, simulando situações de pastejo, sobre a produção de biomassa e o valor nutricional da forragem do trigo de cv. BRS Umbu.

\section{MATERIAL E MÉTODOS}

O experimento foi desenvolvido junto ao Núcleo de Produção Animal (NUPRAN) pertencente ao setor de Ciências Agrárias e Ambientais da Universidade Estadual do Centro-Oeste (UNICENTRO), localizado no município de Guarapuava, PR, no período de maio a novembro de 2011. O clima da região, segundo a classificação de Köppen, é o Cfb (Subtropical mesotérmico úmido), com verões amenos e invernos moderados, sem estação seca definida e com geadas severas. A precipitação anual média é de $1.944 \mathrm{~mm}$, temperatura mínima média anual de $12,7{ }^{\circ} \mathrm{C}$, temperatura máxima média anual de $23,5{ }^{\circ} \mathrm{C}$ e umidade relativa do ar de $77,9 \%$ (IAPAR 2000). As características químicas do solo da área experimental apresentaram valores médios de $\mathrm{pH}$ de $6,7, \mathrm{P}$ de $1,1 \mathrm{mg} \mathrm{dm}^{-3}$, MO de $2,62 \%$, $\mathrm{V}$ de $67,3 \%, \mathrm{~K}^{+}$de $0,2 \mathrm{cmolc}$

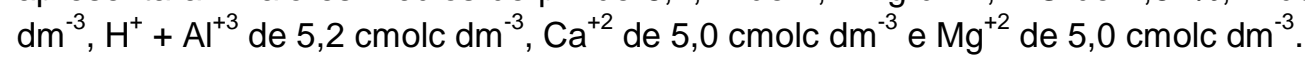

Durante o plantio, realizou-se a adubação de base com $400 \mathrm{~kg} \mathrm{ha}^{-1}$ do fertilizante formulado 04-20-20 $\left(\mathrm{N}-\mathrm{P}_{2} \mathrm{O}_{5}-\mathrm{K}_{2} \mathrm{O}\right)$, seguindo orientações da COMISSÃO DE FERTILIDADE DO SOLO DE SANTA CATARINA E RIO GRANDE DO SUL (2004). A adubação nitrogenada de cobertura foi parcelada em duas aplicações com ureia, sendo a primeira 30 dias após semeadura (DAS) com $140 \mathrm{~kg} \mathrm{ha}^{-1}$ e a segunda com 60 DAS com 250 $\mathrm{kg} \mathrm{ha}^{-1}$.

A semeadura do trigo ocorreu em sistema de plantio direto, de maneira uniforme para os tratamentos, com espaçamento entre linhas de $17 \mathrm{~cm}$, profundidade de semeadura de $4 \mathrm{~cm}$ e com distribuição de 220 sementes $\mathrm{m}^{-2}$. Os tratos culturais sequenciais foram realizados mediante recomendações técnicas para a cultura.

O campo experimental foi constituído de uma área total de $225 \mathrm{~m}^{2}$, distribuída em 15 parcelas de 15 $\mathrm{m}^{2}$ cada $(3 \mathrm{~m} \times 5 \mathrm{~m})$, das quais foi utilizada uma área útil central de $8 \mathrm{~m}^{2}(2 \mathrm{~m} \times 4 \mathrm{~m})$ de cada parcela para as avaliações sequentes. Cada parcela representou-se como uma unidade experimental arranjadas em delineamento de blocos ao acaso com três tratamentos e cinco repetições. Os tratamentos adotados foram simulações de pastejo realizada mediante os seguintes números de cortes: sem corte (controle); um e dois cortes sucessivos.

A simulação de pastejo foi realizada mediante os seguintes tratamentos: sem corte (controle); um e dois cortes sucessivos. O manejo dos tratamentos submetidos a um e a dois cortes seguiram recomendações de FONTANELI et al. (2009) com realização dos cortes das plantas quando estas atingiram altura média de $30 \mathrm{~cm}$, sendo rebaixado a $8 \mathrm{~cm}$ da superfície do solo. O primeiro corte ocorreu 57 DAP. O segundo corte ocorreu quando a forragem apresentou novamente altura média de $30 \mathrm{~cm}, 48$ dias após a 
primeira avaliação (105 DAP).

A produção de biomassa verde $\left(\mathrm{kg} \mathrm{ha}^{-1}\right)$ foi quantificada através da relação entre o peso do material colhido na área útil de cada parcela $\left(8 \mathrm{~m}^{2}\right)$ e a unidade de área, enquanto a produção de biomassa seca $\left(\mathrm{kg} \mathrm{ha}^{-1}\right)$ foi obtida através da produção corrigida pelo teor de matéria seca obtida em estufa de ar forçado à $55^{\circ} \mathrm{C}$.

$\mathrm{Na}$ ocasião de cada corte foi feito medição da altura das plantas e contagem de perfilho. Também foram coletadas duas amostras de $500 \mathrm{~g}$ de cada parcela, sendo uma direcionada para a determinação da matéria seca da planta inteira e posterior análise bromatológica, e outra para segmentação dos componentes estruturais (colmo e folha) e determinação da matéria seca de cada componente. Para a determinação da matéria seca, as amostras foram pré-secas em estufa de ar forçado a $55^{\circ} \mathrm{C}$, até atingirem peso constante (AOAC 1995) e, posteriormente moídas em moinho tipo "Willey" com peneira de $1 \mathrm{~mm}$. Em seguida procedeu-se a determinação da matéria seca definitiva em estufa a $105^{\circ} \mathrm{C}$, o teor de proteína bruta (PB) pelo método micro Kjeldahl, e a matéria mineral (MM) por incineração a $550^{\circ} \mathrm{C}$ segundo AOAC (1995). Os teores da fibra em detergente neutro (FDN) foram determinados conforme VAN SOEST et al. (1991), utilizando a amilase termoestável, a fibra em detergente ácido (FDA) segundo GOERING \& VAN SOEST (1970) e a hemicelulose foi estimada pela diferença entre a FDN e FDA (SILVA \& QUEIROZ 2009).

Os teores de nutrientes digestíveis totais (NDT) foram obtidos via equação sugerida por BOLSEN (1996). Após isto, a energia líquida da lactação foi calculada conforme o NRC (2001) pela equação: ELI $\left(\right.$ mcal kg $\left.{ }^{-1}\right)=0,0245^{\star}$ NDT $(\%)-0,12$. Tomou-se como padrão o valor 0,69 como referência para o valor energético necessário a produção de um litro de leite, a qual, a partir disto foi determinada a produção estimada de leite por hectare através da equação: $\mathrm{PL}=\left[\left(\mathrm{ELI}{ }^{*}\right.\right.$ Produção $M S$ ha $\left.\left.{ }^{-1}\right) \div 0,69\right]$.

Os dados obtidos foram submetidos à análise de variância com comparação de médias pelo teste Tukey a 5\% de significância, por intermédio do programa estatístico SAS (1993).

\section{RESULTADOS E DISCUSSÃO}

Para os sistemas de um e dois cortes houve um atraso para ensilagem de 23 e 38 dias, respectivamente, quando comparados ao tratamento sem cortes, o qual atingiu o ponto ideal para ensilagem (grão farináceo a duro) aos 115 dias após o plantio (DAP) (Tabela 1). Este atraso pode ser justificado como uma resposta fisiológica da planta, na qual há retirada das reservas orgânicas do sistema radicular da planta para gerar crescimento aéreo através dos sistemas meristemáticos (TAIZ \& ZEIGER 1991). Por conseguinte, esta resposta acaba gerando uma maior duração de ciclo para a realização da silagem, o que corrobora com os dados do presente trabalho.

Tabela 1. Ciclo para a ensilagem, densidade populacional de perfilhos, altura de plantas na ensilagem e relação colmo:folha na ensilagem do trigo BRS Umbu, submetido a diferentes manejos de cortes.

Table 1. Silage cycle, tiller population density, plant height in silage and stem ratio: leaf in BRS Umbu wheat silage, subjected to different cut management.

\begin{tabular}{lcccc}
\hline Manejos de corte & $\begin{array}{c}\text { Ciclo para ensilagem } \\
\text { após corte } \\
\text { (DAP) }\end{array}$ & $\begin{array}{c}\text { Densidade } \\
\text { populacional de } \\
\text { perfilhos }\left(\mathrm{m}^{2}\right)\end{array}$ & $\begin{array}{c}\text { Altura de planta na } \\
\text { ensilagem }(\mathrm{cm})\end{array}$ & $\begin{array}{c}\text { Relação colmo: } \\
\text { folha }\end{array}$ \\
\cline { 1 - 4 } Sem corte & 115 & $912,2 \mathrm{a}$ & $75,6 \mathrm{a}$ & $4,14 \mathrm{a}$ \\
Um corte & 138 & $820,8 \mathrm{a}$ & $64,4 \mathrm{~b}$ & $2,36 \mathrm{~b}$ \\
Dois Cortes & 153 & $577,6 \mathrm{~b}$ & $47,4 \mathrm{c}$ & $2,24 \mathrm{~b}$ \\
Média & - & 770,2 & 62,46 & 2,91 \\
CV, \%. & - & 11,08 & 7,36 & 27,12 \\
Probabilidade & - & 0,0007 & 0,0001 & 0,0087 \\
\hline
\end{tabular}

Médias, seguidas de letras minúsculas na coluna diferem entre si pelo teste Tukey a $5 \%$ de probabilidade.

A altura de planta no momento da ensilagem entre os tratamentos obteve diferença significativa $(p<0,05)$, sendo maior para o tratamento sem corte $(75,6 \mathrm{~cm})$, que também apresentou maior densidade populacional $\left(912,2\right.$ perfilhos $\left.\mathrm{m}^{-2}\right)$ e maior relação colmo:folha $(4,14)$, em contraste com o regime de dois cortes, que apresentou valores inferiores para todos os parâmetros avaliados. Com o passar do primeiro e depois do segundo corte a planta rebrota em épocas mais distantes daquelas consideradas ideias para seu pleno desenvolvimento, o que acaba por reduzir sua taxa fotossintética e potencial para crescimento (CARLETTO et al. 2015). Aliado a isso, a disponibilidade dos nutrientes, com ênfase ao nitrogênio, já não são as mesmas, fazendo com a planta que não foi manejada com cortes apresentasse tais valores superiores. HOLLAND et al. (2019) comprovaram que sem a correção necessária com nitrogênio e potássio, 
tanto a produção de forragem subsequente quando uma possível colheita de grãos será afetada.

BARTMEYER et al. (2011) ao avaliarem trigo de duplo propósito após período de pastejo por bovinos de corte, notou diferença significativa na altura das plantas, sendo de menor magnitude para os tratamentos em pastejo comparado com o tratamento sem pastejo. Tais fatos corroboram com os dados observados no presente experimento, em que a altura de planta também foi consideravelmente menor nos sistemas com maior número de cortes.

Além disto, FONTANELI et al. (2009) avaliaram o rendimento da forragem precoce em um corte, proveniente do rebrote de três genótipos de trigo, obtiveram altura de planta de $77 \mathrm{~cm}$ na ensilagem, para 0 trigo BRS Umbu, enquanto neste experimento foi obtido altura de $76,5 \mathrm{~cm}$ na ensilagem para o sistema sem cortes, $64 \mathrm{~cm}$ para um corte, e $47,4 \mathrm{~cm}$ para dois cortes. Tal acontecimento pode ser positivo, pois segundo QUATRIN et al. (2017) em locais de elevadas altitudes e com ventos fortes, a produtividade do trigo pode ser comprometida pelo acamamento das plantas com porte elevado. Nesse sentido, a desfolha favorece a redução do acamamento pela redução no comprimento de colmos e produção de espigas menores (BORTOLINI et al. 2004, CARLETTO et al. 2015).

A relação colmo:folha decresceu com o manejo de cortes, com valores de 2,36 e 2,24 para os sistemas com um e dois cortes sucessivos, respectivamente. Fato semelhante foi constatado por MEINERZ et al. (2012) que obtiveram valor médio para a relação colmo:folha igual a 1,7 quando as plantas de trigo foram submetidas a três cortes, mostrando que a relação colmo:folha tende a diminuir com o aumento do número de cortes da forragem. Essa diminuição está atrelada ao fato que durante a rebrota, as folhas são expandidas mais rapidamente dos seus colmos já emitidos, enquanto que durante o crescimento inicial, as folhas são emitidas juntamente com o colmo, dividindo a energia disponível na planta (TAIZ \& ZEIGER 1991).

LEHMEN et al. (2014) avaliaram silagens de cereais de inverno, não submetidas à sistemas de corte, obtiveram com o trigo BRS Umbu ciclo para o ensilamento de 152 dias, altura de $83 \mathrm{~cm}$ da planta e rendimento de $8.688 \mathrm{~kg}_{\text {de }} \mathrm{MS} \mathrm{ha}^{-1}$, sendo o parâmetro que mais se aproximou dos valores do sistema sem corte do presente experimento, a altura de planta.

A produção de biomassa verde de forragem ensilável obteve diferença significativa $(p<0,05)$, sendo maior para o sistema sem cortes $\left(21.913 \mathrm{~kg} \mathrm{ha}^{-1}\right.$; Tabela 2). A resposta fisiológica supracitada, em virtude da diminuição da altura de planta, ocasiona por consequência a redução da quantidade de biomassa verde por hectare (19.282 e $20.289 \mathrm{~kg} \mathrm{ha}^{-1}$ para um e dois cortes, respectivamente), o que também foi consoante neste trabalho. Em trabalho semelhante, mas com a cv. Tarumã, ZILIO et al. (2018) obtiveram produção acumulada superior no segundo corte em relação ao corte único.

Tabela 2. Produção de biomassa verde e biomassa seca de forragem aos 57 e 105 DAP, ensilagem e biomassa acumulada do trigo BRS Umbu, submetido a sistemas de cortes.

Table 2. Production of green biomass and dry forage biomass at 57 and 105 DAP, silage and accumulated biomass of BRS Umbu wheat, submitted to cutting systems.

\begin{tabular}{|c|c|c|c|c|}
\hline \multirow[t]{2}{*}{ Sistemas de corte } & \multicolumn{2}{|c|}{ Cortes } & \multirow{2}{*}{$\begin{array}{l}\text { Forragem } \\
\text { ensilável }\end{array}$} & \multirow{2}{*}{$\begin{array}{l}\text { Biomassa } \\
\text { acumulada }\end{array}$} \\
\hline & 57 DAP & 105 DAP & & \\
\hline & \multicolumn{4}{|c|}{ Biomassa verde, $\mathrm{kg} \mathrm{ha}^{-1}$} \\
\hline Sem cortes & - & - & $21.913 \mathrm{a}$ & $21.913 \mathrm{a}$ \\
\hline Um corte & 4.656 & - & $14.625 \mathrm{~b}$ & $19.282 \mathrm{a}$ \\
\hline Dois cortes & 5.399 & 9.596 & $5.294 \mathrm{c}$ & $20.289 a$ \\
\hline Média & - & - & 13.944 & 20.495 \\
\hline $\mathrm{CV}, \%$ & - & - & 9,24 & 6,46 \\
\hline Probabilidade & - & - & 0,0001 & 0,0799 \\
\hline & \multicolumn{4}{|c|}{ Biomassa seca, $\mathrm{kg} \mathrm{ha}^{-1}$} \\
\hline Sem cortes & - & - & $10.926 \mathrm{a}$ & 10.926 a \\
\hline Um corte & 772 & - & $7.989 \mathrm{~b}$ & $8.761 \mathrm{~b}$ \\
\hline Dois cortes & 906 & 1.873 & $3.514 \mathrm{c}$ & $6.293 \mathrm{c}$ \\
\hline Média & - & - & 7.476 & 8.660 \\
\hline CV,$\%$ & - & - & 11,94 & 9,19 \\
\hline Probabilidade & - & - & 0,0001 & 0,0001 \\
\hline
\end{tabular}

Médias seguidas de letras minúsculas para coluna diferem entre si pelo teste Tukey a $5 \%$.

FONTANELI et al. (2009) obtiveram produção de biomassa verde total de $19.222 \mathrm{~kg} \mathrm{ha}^{-1}$ do trigo BRS Umbu para o sistema de um corte, valor próximo ao do encontrado neste experimento, enquanto a biomassa seca total encontrada pelo mesmo autor foi de $6.017 \mathrm{~kg} \mathrm{ha}^{-1}$, valor inferior ao aqui encontrado. 
De maneira oposta, não houve diferença estatística na biomassa verde acumulada entre os diferentes regimes de corte, apresentando média de $20.495 \mathrm{~kg} \mathrm{ha}{ }^{-1}$. Porém a biomassa seca acumulada foi estatisticamente maior para o tratamento sem cortes (10.926 kg ha ${ }^{1}$ ), seguido pelo tratamento com um corte (8.765 kg ha-1) e com dois cortes (6.293 kg ha $\left.{ }^{-1}\right)$.

A baixa produção de biomassa seca acumulada nos sistemas de um e dois cortes é justificada pela baixa percentagem de MS dos cortes anteriores (16,9\% e 16,7\%, respectivamente), e um incremento para o segundo corte, ficando em 19,2\% de MS (Tabela 3), ou seja, a taxa de umidade das plantas nestes estádios era elevada. E ainda, segundo BORTOLINI et al. (2004) o sistema de desfolha provoca estresse na planta pela remoção da área foliar, e conforme o momento e intensidade da desfolha, haverá acometimento em maior ou menor grau do rendimento da forragem.

Tabela 3. Teores de matéria seca (\%) de planta inteira e de seus componentes colmo e folhas para o corte de forragem aos 57 e 105 dias após o plantio (DAP), e no momento da ensilagem, de plantas de trigo cv. BRS Umbu, submetidas a sistemas de cortes.

Table 3. Content of dry matter (\%) of whole plant and its stem and leaf components for cutting forage at 57 and 105 days after planting (DAP), and at the time of ensiling, of wheat plants cv. BRS Umbu, subjected to cutting systems.

\begin{tabular}{|c|c|c|c|}
\hline Sistemas de cortes & 57 DAP & 105 DAP & Forragem ensilável \\
\hline & \multicolumn{3}{|c|}{ Teor de MS do colmo, \%. } \\
\hline Sem cortes & - & - & $43,6 \mathrm{c}$ \\
\hline Um corte & 15,3 & - & $53,8 b$ \\
\hline Dois cortes & 15,7 & 21,5 & $66,3 \mathrm{a}$ \\
\hline Média & - & - & 54,6 \\
\hline $\mathrm{CV}, \%$ & - & - & 6,39 \\
\hline Probabilidade & - & - & 0,0001 \\
\hline \multicolumn{4}{|c|}{ Teor de MS das folhas, \%. } \\
\hline Sem cortes & - & - & $50,7 \mathrm{~b}$ \\
\hline Um corte & 17,8 & - & $65,1 \mathrm{a}$ \\
\hline Dois cortes & 17,1 & 20,1 & $61,7 \mathrm{a}$ \\
\hline Média & - & - & 59,2 \\
\hline $\mathrm{CV}, \%$ & - & - & 9,97 \\
\hline Probabilidade & - & - & 0,0116 \\
\hline \multicolumn{4}{|c|}{ Teor de MS da planta Inteira, \%. } \\
\hline Sem cortes & 0 & 0 & $49,9 \mathrm{~b}$ \\
\hline Um corte & 16,9 & 0 & $54,7 \mathrm{~b}$ \\
\hline Dois cortes & 16,7 & 19,2 & $63,2 \mathrm{a}$ \\
\hline Média & - & - & 55,9 \\
\hline $\mathrm{CV}, \%$ & - & - & 7,63 \\
\hline Probabilidade & - & - & 0,0034 \\
\hline
\end{tabular}

Médias seguidas de letras minúsculas para coluna diferem entre si pelo teste Tukey a 5\%.

Foi verificado, no momento da ensilagem, maiores teores de matéria seca da planta inteira para o tratamento que recebeu dois cortes $(63,2 \%)$, enquanto que para os tratamentos sem corte e com um corte, também apresentaram acúmulo acentuado no teor de matéria seca na fase final do ciclo, com média de $49,9 \%$ e 54,7\%, respectivamente, diferindo-se estatisticamente do valor encontrado para o sistema de dois cortes, mas não diferindo-se entre si. Os teores de matéria seca tenderam ao aumento com a sucessão de cortes, notando-se que o sistema sem cortes obteve, no ponto de forragem ensilável, os menores índices de matéria seca para colmo e folhas e consequentemente, para planta inteira.

Com a sucessão de cortes, nos tratamentos de um corte e dois cortes, as folhas apresentaram incremento na taxa de matéria seca, concomitantemente com a tendência de decréscimo da produção de biomassa verde, como pode ser observado na Tabela 4. Além disto, tal fato também foi confirmado por MEINERZ et al. (2012) que observaram aumento na taxa de acúmulo diário de matéria seca nas lâminas foliares, e decréscimo da produção de biomassa seca na sucessão de cortes, o que pode ser explicado pelo avanço do ciclo fisiológico.

Como mostrado na Tabela 4, a produção de colmo em $\mathrm{kg} \mathrm{ha}^{-1}$ no sistema sem cortes foi quatro vezes maior do que no sistema com um e dois cortes, apresentando relação colmo:folha de 4,1 sendo que este índice decresce com o aumento do número de cortes. A produtividade elevada da forragem está relacionada com a maior proporção de colmo em relação a folhas, pois por serem mais densos contribuem fortemente para a biomassa seca da planta (HASTENPFLUG et al. 2011, SANTOS et al. 2015). 
Tabela 4. Produção de colmo e folhas do trigo cv. BRS Umbu em $\mathrm{kg} \mathrm{ha}^{-1}$, submetido a diferentes sistemas de cortes.

Table 4. Production of stalk and leaves of wheat $\mathrm{cv}$. BRS Umbu in $\mathrm{kg} \mathrm{ha}^{-1}$, submitted to different cutting systems.

\begin{tabular}{llll}
\hline Sistemas de cortes & 57 DAP & 105 DAP & Forragem ensilável \\
\hline Sem cortes & - & Produção de colmo, $\mathrm{kg} \mathrm{ha}^{-1}$. & \\
Um corte & 136,65 & - & $4.121,2 \mathrm{a}$ \\
Dois cortes & 95,73 & - & $3.193,6 \mathrm{~b}$ \\
Média & - & 164,82 & $954,1 \mathrm{c}$ \\
CV, \% & - & - & $2.756,3$ \\
Probabilidade & - & - & 15,61 \\
Sem cortes & - & Produção de folhas, $\mathrm{kg} \mathrm{ha}^{-1}$. & 0,0001 \\
Um corte & 634,61 & - & $1.038,2 \mathrm{~b}$ \\
Dois cortes & 676,3 & - & $1.381,4 \mathrm{a}$ \\
Média & - & - & $420,8 \mathrm{c}$ \\
CV, \% & - & - & 946,8 \\
Probabilidade & - & - & 15,38 \\
\hline
\end{tabular}

Médias seguidas de letras minúsculas para coluna diferem entre si pelo teste Tukey a 5\%.

A Tabela 4 ainda apresenta os valores médios para a composição de plantas de trigo cv. BRS Umbu, no momento dos cortes da forragem e da ensilagem. Observa-se que no primeiro corte dos sistemas de um e dois cortes, e no segundo corte do sistema de dois cortes, as plantas apresentavam acentuado crescimento vegetativo, pois a produção de folhas apresentou valores superiores aos encontrados para a produção de colmo.

De acordo com FONTANELI et al. (2009) os cereais de inverno adaptados ao sistema de duplo propósito devem possuir grande capacidade de recuperação de sua área foliar após o pastejo, pois o rendimento de grãos depende da eficiência fotossintética das plantas, as quais precisam de uma adequada área foliar para captação dos raios solares. O sistema de um corte obteve produção de $1.381,4 \mathrm{~kg}$ de folhas $\mathrm{ha}^{-1}$ no corte para ensilagem, enquanto produziu $634,61 \mathrm{~kg}$ de folhas ha ${ }^{-1}$ no primeiro corte. Diferentemente do que ocorreu no tratamento com dois cortes, que teve produção de $676,3 \mathrm{~kg} \mathrm{ha}^{-1}$ no primeiro corte, aumentando consideravelmente no segundo corte e reduzindo drasticamente no ponto de ensilagem para $420,8 \mathrm{~kg} \mathrm{ha}^{-1}$.

MEINERZ et al. (2012) afirmam que comparativamente com a primeira avaliação, a sucessão de cortes tende a reduzir a produção de biomassa de lâminas foliares em genótipos de trigo, incluindo o cv. BRS Umbu, pois a intensa desfolhação reduz a taxa de fotossíntese e a alteração na alocação relativa de fotoassimilados (PARSONS et al. 1988, QUATRIN et al. 2017).

Isto é constatável no sistema com dois cortes deste experimento, que apesar de aumentar significativamente a produção no segundo corte, diminuiu no corte para ensilagem. PARSONS et al. (1988) ainda apontam que a produção de colmos em $\mathrm{kg} \mathrm{ha}^{-1}$, com a sucessão de cortes é crescente, obtendo $416 \mathrm{~kg} \mathrm{ha}^{-1}, 644 \mathrm{~kg} \mathrm{ha}^{-1}$, e $1.468 \mathrm{~kg} \mathrm{ha}^{-1}$, do primeiro ao terceiro corte, o que novamente é comprovado no sistema de dois cortes do presente experimento, que teve $95,73 \mathrm{~kg} \mathrm{ha}^{-1}, 164,82 \mathrm{~kg} \mathrm{ha}^{-1}$, e 954,1 $\mathrm{kg} \mathrm{ha}^{-1}$, com a sucessão de cortes.

O índice de produtividade de folhas em relação ao colmo, no primeiro corte, para os sistemas com um e dois cortes são superiores. Segundo HASTENPFLUG et al. (2011) a massa de forragem composta exclusivamente de folhas implica maior concentração de proteína bruta na matéria seca e melhor qualidade da forragem.

Com o avanço dos estádios de desenvolvimento da planta, ocorre diminuição da produtividade de folhas e alongamento dos colmos, assim a forragem apresenta queda na proteína bruta e, portanto, nos níveis nutricionais (SANTOS et al. 2015). Apesar desse entendimento, não foi observado influência do sistema de corte em relação ao teor de PB nas plantas no ponto de ensilagem, haja vista que se trata de um avanço da idade mas não do ciclo fisiológico, justamente por interrupção deste pelo corte.

A análise bromatológica da forragem colhida ao primeiro corte apresentou média de 8,20\% para o teor de MM, e ao segundo corte redução desse teor para 4,49\%, o que poderia estar relacionado ao fato dos cortes reduzirem a participação de colmos e aumentarem a participação de folhas na planta, obtendo maior porção vegetativa com compostos orgânicos (Tabela 5). Valor estatisticamente superior foi obtido para as plantas que originariam a silagem do tratamento sem corte, em comparação aos tratamentos com 
um e dois cortes, respectivamente.

Tabela 5. Teores médios de matéria mineral (MM), proteína bruta (PB), fibra em detergente neutro (FDN), fibra em detergente ácido (FDA) e hemicelulose (HEM) da forragem e plantas ensiladas de trigo cv. BRS Umbu submetidas a sistemas de cortes.

Table 5. Average contents of mineral matter (MM), crude protein (CP), neutral detergent fiber (NDF), acid detergent fiber (ADF) and hemicellulose (HEM) of forage and ensiled wheat plants cv. BRS Umbu subjected to cutting systems.

\begin{tabular}{|c|c|c|c|}
\hline \multirow[t]{2}{*}{ Sistemas cortes } & \multicolumn{3}{|c|}{ Composição bromatológicas } \\
\hline & 57 DAP & 105 DAP & Forragem ensilável \\
\hline & \multicolumn{3}{|c|}{$\mathrm{MM}, \%$ na $\mathrm{MS}$} \\
\hline Sem cortes & - & - & $4,62 \mathrm{a}$ \\
\hline Um corte & 7,31 & - & $2,07 \mathrm{~b}$ \\
\hline Dois cortes & 9,09 & 4,49 & $2,30 \mathrm{~b}$ \\
\hline Média & 8,20 & - & 3,00 \\
\hline $\mathrm{CV}, \%$ & - & - & 37,06 \\
\hline \multirow{2}{*}{ Probabilidade } & - & - & 0,0123 \\
\hline & \multicolumn{3}{|c|}{$\mathrm{PB}, \%$ na MS } \\
\hline Sem cortes & - & - & $4,60 \mathrm{a}$ \\
\hline Um corte & 21,08 & - & $5,03 \mathrm{a}$ \\
\hline Dois cortes & 19,79 & 16,73 & $3,94 \mathrm{a}$ \\
\hline Média & 20,43 & - & 4,52 \\
\hline $\mathrm{CV}, \%$ & - & - & 55,26 \\
\hline \multirow[t]{2}{*}{ Probabilidade } & - & - & 0,7909 \\
\hline & \multicolumn{3}{|c|}{ FDN, \% na MS } \\
\hline Sem cortes & - & - & $60,30 \mathrm{a}$ \\
\hline Um corte & 58,87 & - & $51,43 a$ \\
\hline Dois cortes & 57,20 & 58,48 & $55,10 a$ \\
\hline Média & 58,03 & - & 55,61 \\
\hline $\mathrm{CV}, \%$ & - & - & 10,13 \\
\hline \multirow[t]{2}{*}{ Probabilidade } & - & - & 0,0991 \\
\hline & \multicolumn{3}{|c|}{ FDA, \% na MS } \\
\hline Sem cortes & - & - & $33,51 \mathrm{a}$ \\
\hline Um corte & 33,40 & - & 32,41 a \\
\hline Dois cortes & 35,18 & 33,55 & $32,85 \mathrm{a}$ \\
\hline Média & 34,29 & - & 32,93 \\
\hline $\mathrm{CV}, \%$ & - & - & 9,80 \\
\hline \multirow[t]{2}{*}{ Probabilidade } & - & - & 0,8657 \\
\hline & \multicolumn{3}{|c|}{ HEM, \% na MS } \\
\hline Sem cortes & - & - & $26,79 \mathrm{a}$ \\
\hline Um corte & 25,48 & - & $19,68 \mathrm{a}$ \\
\hline Dois cortes & 22,59 & 23,92 & $21,98 \mathrm{a}$ \\
\hline Média & 24,04 & - & 22,81 \\
\hline $\mathrm{CV}, \%$ & - & - & 26,88 \\
\hline Probabilidade & - & - & 0,2345 \\
\hline
\end{tabular}

Médias seguidas de letras minúsculas para coluna diferem entre si pelo teste Tukey a 5\%.

BARTMEYER et al. (2011) verificaram composição bromatológica para o trigo pastejado aos 50 dias após emergência igual a 33,02\% de PB, 24,17\% de FDA e 45,54\% de FDN, e quando submetido ao pastejo aos 95 dias após a emergência o teor de PB foi de 13,16\%, o FDA de 32,98\% e o FDN de 62,96\%. Enquanto nesse experimento notou-se o decréscimo proteico da forragem, porém não foi observado aumento na fração fibrosa (FDN e FDA). Para os teores de FDN, FDA e hemicelulose não foram observadas diferenças estatísticas entre os tratamentos. Em comparação de manejos semelhantes ao nosso, ZILIO et al. (2018) descreveram redução no teor de PB da cv. Tarumã do primeiro para o segundo corte.

MEINERZ et al. (2011) alcançaram valores para a cultivar BRS Umbu de 23,19\% de PB, 17,14\% de FDA e 52,99\% de FDN quando o tratamento foi com um corte de forragem. No tratamento com dois cortes de forragem os valores foram de $25,53 \%$ de PB, $27,52 \%$ de FDA e $60,83 \%$ de FDN. Havendo assim, acréscimo no teor de todos os parâmetros avaliados, enquanto no experimento houve decréscimo dos mesmos parâmetros. 
No entanto, embora para muitos aspectos nutricionais não tenha se obtido diferença significativa, o potencial energético e de produção estimada de leite por hectare apresentaram resultados interessantes. Nota-se na intersecção dos dados (Figura 1), que o tratamento com um corte obteve maior valor energético, apresentando $1,476 \mathrm{Mcal}_{\mathrm{kg}}$ de $\mathrm{MS}^{-1}$ de energia líquida de lactação, entretanto, o potencial de produção estimada de leite foi intermediário $\left(31.615 \mathrm{~kg} \mathrm{ha}^{-1}\right)$, obtendo valores inferiores ao tratamento sem cortes $\left(46.764 \mathrm{~kg} \mathrm{ha}^{-1}\right)$.

a)

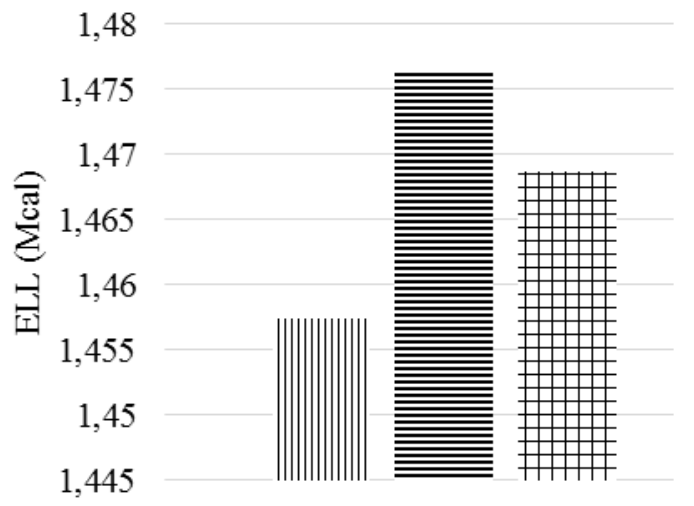

b)

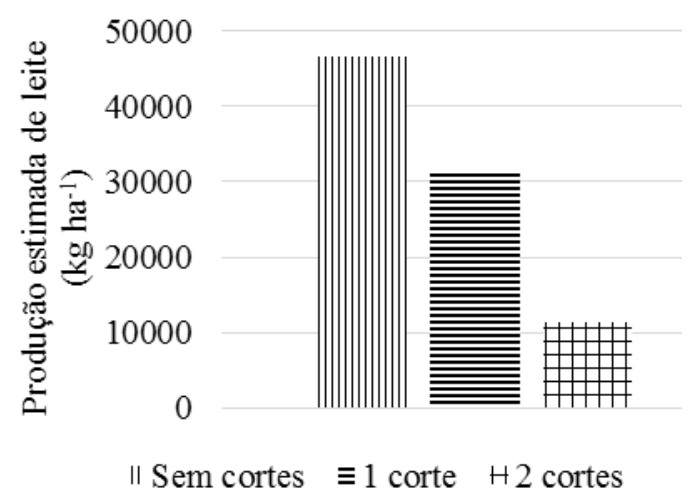

Figura 1. Energia líquida de lactação $\left(\mathrm{Mcal} \mathrm{kg} \mathrm{MS}^{-1}\right)$ (a) e produção estimada de leite $\left(\mathrm{kg} \mathrm{ha}^{-1}\right)$ (b) do trigo cv. BRS Umbu manejado em regimes de cortes.

Figure 1. Net energy of lactation (Mcal $\mathrm{kg} \mathrm{DM}^{-1}$ ) (a) and estimated milk production ( $\left.\mathrm{kg} \mathrm{ha}^{-1}\right)$ (b) from wheat cv. BRS Umbu managed in cutting regimes.

Sendo assim, pode-se gerar recomendações distintas de acordo com o objetivo geral da propriedade. Ao se analisar as condições de uma propriedade pode-se optar pelo sistema sem nenhum corte ou com o sistema com um corte, dependendo se o objetivo final seja maior produção por área ou maior valor energético do alimento.

Desta forma, pelos dados apresentados no presente trabalho, o trigo cv. BRS Umbu comprovou sua versatilidade, sendo uma alternativa viável no tocante a integração lavoura pecuária, podendo inclusive ser utilizada no uso sucessivo de produção de forragem e produção de grãos. No entanto, endossa-se que existe limitação de produção de regimes acima de um corte.

\section{CONCLUSÃO}

O aumento no número de cortes não reduz o rendimento de biomassa verde acumulado, mas, uma diminuição expressiva no percentual de folhas pode levar a menores produções de biomassa seca. Como a bromatologia não foi alterada pelo regime de cortes, percebe-se melhores resultados produtivos em sistema de um corte e/ou pastejo.

\section{REFERÊNCIAS}

AOAC. 1995. Association of Official Analytical Chemists. Official methods of analysis. 16.ed. Washington: AOAC. 2000p. BARTMEYER TN et al. 2011. Trigo de duplo propósito submetido ao pastejo de bovinos nos campos gerais. Pesquisa Agropecuária Brasileira 46: 1247-1253.

BOLSEN KK. 1996. Silage Technology. In: Australian Maize Conference. Proceedings... Queensland: Gatton College. p.1-30.

BORTOLINI PC et al. 2004. Cereais de inverno submetidos ao corte no sistema de duplo propósito. Revista Brasileira de Zootecnia 33: 45-50.

CARLETTO $R$ et al. 2015. Efeito do manejo de cortes sucessivos sobre a produção e qualidade de grãos de trigo duplo propósito. Revista Acadêmica Ciência Animal 13: 1-8.

CQFS-RS/SC. 2004. COMISSÃO DE QUÍMICA E FERTILIDADE DO SOLO RS/SC - Manual de adubação e de calagem para os Estados do Rio Grande do Sul e de Santa Catarina. 10.ed. Porto Alegre: SBCS. 400p.

DEEN W et al. 2019. Annual Cereal Cover Crops Following Winter Wheat Produce High Quality Fall Forage. Agronomy Journal 111: 1634-1642.

FONTANELI RS et al. 2009. Rendimento e valor nutritivo de cereais de inverno de duplo propósito: forragem verde e silagem ou grãos. Revista Brasileira de Zootecnia 38: 2116-2120.

GOERING HK \& VAN SOEST PJ. 1970. Forage fiber analysis: apparatus reagents, procedures and some applications. 
Washington. Agricultural Handbook. p.379.

HASTENPFLUG M et al. 2011. Cultivares de trigo duplo propósito submetidos ao manejo nitrogenado e a regimes de corte. Arquivo Brasileiro de Medicina Veterinária e Zootecnia 63: 196-202.

HOLLAND JE et al. 2019. Biomass, feed quality, mineral concentration and grain yield responses to potassium fertiliser of dual-purpose crops. New Zealand Journal of Agricultural Research 62: 476-494.

IAPAR. 2000. Instituto Agronômico do Paraná. Cartas Climáticas do Paraná. Versão 1.0. (CD).

LEHMEN RI et al. 2014. Rendimento, valor nutritivo e características fermentativas de silagens de cereais de inverno. Ciência Rural 44: 1180-1185.

MEINERZ GR et al. 2011. Silagem de cereais de inverno submetidos ao manejo de duplo propósito. Revista Brasileira de Zootecnia 40: 2097-2104.

MEINERZ GR et al. 2012. Produtividade de cereais de inverno de duplo propósito na depressão central do Rio Grande do Sul. Revista Brasileira de Zootecnia 41: 873-882.

NRC. 2001. National Research Council. Nutrient requirements of dairy cattle.7.ed. Washington: National Academy Press. 360p.

NEUMANN M et al. 2014. Ensilagem: Estratégias visando maior produção de leite. In: I Simpósio Brasileiro de Ruminantes Leiteiros. Anais... Uberlândia: UFU. p.130-166.

PARSONS AJ et al. 1988. Use of a model to optimize the interaction between frequency and severity of intermittent defoliation and to provide a fundamental comparison of the continuous and intermittent defoliation of grass. Grass and Forage Science 43: 49-59.

QUATRIN MP et al. 2017. Produtividade de genótipos de trigo duplo propósito submetidos ao pastejo com vacas em lactação. Arquivo Brasileiro de Medicina Veterinária e Zootecnia 69: 1615-1623.

SANTOS HP et al. 2015. Avaliação de trigo para grãos e duplo propósito, sob plantio direto. Revista Brasileira de Ciências Agrárias 10: 43-48.

SAS. 1993. SAS INSTITUTE. SAS/STAT. User's guide statistcs. 4.ed. Version 6. North Caroline. SAS. 943p.

SILVA DJ \& QUEIROZ AC. 2009. Análise de alimentos, métodos químicos e biológicos. 3.ed. Viçosa: UFV. 235p.

SILVA EP et al. 2008. Fatores abióticos envolvidos na tolerância de trigo à geada. Pesquisa Agropecuária Brasileira 43: 1257-1265.

TAIZ L \& ZEIGER E. 1991. Plant Physiology. Califórnia: The Benjamin/Cummings Publishings Company. 565p.

VAN SOEST PJ et al. 1991. Methods for dietary fiber, neutral detergent fiber, and nonstarch polysaccharides in relation to animal nutrition. Journal of Dairy Science 74: 3583-3597.

ZILIO M et al. 2018. Agronomic performance of wheat BRS Tarumã under different sowing densities, nitrogen fertilization and cutting managements. Científica 46: 1-7. 